\title{
Those who can teach, should
}

\author{
Education is a central mission of universities. Emphasizing creative and passionate teaching by all academic staff is \\ essential for maintaining educational quality while supporting vigorous research.
}

\begin{abstract}
$\mathrm{C}$ lassroom teaching is central to our concept of the modern university and remains the primary means by which knowledge is transmitted from professors to young scientists. However, because publication records and external funding success are the major criteria for advancement in science, for most tenure track faculty, research takes priority over teaching and service. Additionally, the roles of professors are increasingly stretched with nontraditional activities such as consulting and development of companies. These demands come at the cost of having less time and energy to dedicate to teaching, with the frequent result that teaching faculty are employed to fill in the gaps. Rather than view this shift as a temporary or disagreeable solution, faculty and administrators must acknowledge the importance of teaching for all professors and the value of nonresearch faculty who are committed to classroom teaching. Thus, in balancing the teaching and research resources of faculty members, the first steps to revitalizing education are encouraging, employing and rewarding excellent teachers.
\end{abstract}

Professors and students reap many benefits from the university classroom. By teaching introductory courses, faculty members are constantly reminded of the broader underpinnings of their own scientific expertise. Advanced courses offer faculty the opportunity to delve into more specialized topics that may spur new directions for the professor's research. For students, introductory courses provide initial exposure to a new subject, and positive experiences will significantly influence career decisions, as well as enhance scientific literacy in general. In advanced courses, students have the chance to build specialized knowledge, guided by scientists at the forefront of the subject area. These experiences provide a unique opportunity for students to learn the intellectual heritage of their fields and to develop critical thinking skills that are crucial for success in the research laboratory.

Given the numerous demands on today's professoriate, however, many faculty appear to have forgotten the benefits of teaching. Some are even conditioned to ignore it based on the mistaken impression that devoting time to teaching necessarily has a negative impact on research. The first task, then, in improving education is to encourage professors to renew their dedication to teaching. Providing teacher training for faculty, and young faculty in particular, will both enhance teaching capabilities and reinforce the value of fully engaging in the teaching experience. Faculty should also seek external resources such as educational researchers who have extensive experience analyzing or developing teaching methods and would welcome an opportunity to put new ideas into practice.

Beyond rejuvenating current teaching habits, departments and universities must place greater emphasis on employing able and enthusiastic teachers. Scant attention is paid to a scientist's teaching resume in comparison to the extensive paperwork that details a proposed research program in the process of hiring faculty. With so many prospective professors on the market, search committees must seek to identify candidates that will significantly contribute to both research and teaching.

Teaching faculty can also play a pivotal role in enhancing undergraduate education. In addition to the excitement that dedicated teachers bring to the classroom, they may be able to present a more balanced view of an introductory topic as they are not focused on a specific research field, and they have more time to seek alternate teaching methods. The current system, however, does not take full advantage of the talents of these scientists. The AAUP Contingent Faculty Index (http://www.aaup.org/AAUP/issues) reported in 2006 that nearly $30 \%$ of all full-time faculty are not on the tenure track, and $47 \%$ of all faculty are part-time employees; the biannual Campus Equity Week (http:// www.campusequityweek.org), held this year in early November, seeks to highlight issues that confront these disenfranchised faculty. Even setting aside specific problems that arise from lack of job security or benefits, however, it is perhaps not surprising that short-term employees would not be invested in the long-term curriculum of their department, or that teachers whose jobs depend on student evaluations would be reluctant to try innovative and thus uncertain educational plans. Notably, in the midst of the academic search for 2008, few advertisements specifically call for teachers (at the end of October 2007, only 6 of more than 200 jobs at http://www.naturejobs.com seek teaching faculty), yet it is likely that schools are already well aware of their needs to sufficiently staff courses for the upcoming year. By hiring teaching faculty early, and for the long term, they will be more integrated and invested in the educational mission of departments and universities.

Finally, the science community must do a better job of recognizing teaching. Developing standardized methods to quantitatively assess teaching performance would provide much-needed metrics for evaluating contributions in tenure and award decisions. Additionally, the current reward structure must be revamped to value teaching: although a few funding agencies have attempted to underscore the importance of integrating research and educational goals through 'broader impact' statements (http://www.nsf.gov/pubs/2002/nsf022/bicexamples.pdf), others seek to free distinguished researchers from the constraints of teaching and other 'administrative' tasks (http://www.epsrc.ac.uk/ ResearchFunding/Opportunities/Fellowships/LF.htm, http://www. bbsrc.ac.uk/funding/fellowships/Welcome.html), thereby reinforcing the misguided view that teaching should be secondary to research.

The challenges of maintaining a vibrant academic department are numerous, but reaching out to inspire the next generation of scientific leaders must remain a fundamental goal of every university. Within this framework, all teachers, including research-active and teaching faculty, are part of the solution of enhancing the educational experience. 